\title{
Trihalomethanes in Comerio Drinking Water and Their Reduction by Nanostructured Materials
}

\author{
Jorge Hernández Bourdon, Francisco Márquez Linares \\ School of Science and Technology, Universidad del Turabo, Gurabo, Puerto Rico \\ Email: jhernandezbourdon@gmail.com
}

Received 17 January 2014; revised 17 February 2014; accepted 25 February 2014

Copyright (C) 2014 by authors and Scientific Research Publishing Inc.

This work is licensed under the Creative Commons Attribution International License (CC BY). http://creativecommons.org/licenses/by/4.0/

\section{Open Access}

\section{Abstract}

The formation of disinfection by-products (DBPs) during chlorination of drinking water is an issue which has drawn significant scientific attention due to the possible adverse effects that these compounds have on human health and the formation of another DBPs. Factors that affect the formation of DBPs include: chlorine dose and residue, contact time, temperature, $\mathrm{pH}$ and natural organic matter (NOM). The most frequently detected DBPs in drinking water are trihalomethanes (THMs) and haloacetic acids (HAAs). The MCLs are standards established by the United States Environmental Protection Agency (USEPA) for drinking water quality established in Stage 1, Disinfectants and Disinfection Byproducts Rule (DBPR), and they limit the amount of potentially hazardous substances that are allowed in drinking water. The water quality data for THMs were evaluated in the Puerto Rico Aqueduct and Sewer Authority (PRASA). During this evaluation, the THMs exceeded the maximum contamination limit (MCLs) for the Comerio Water Treatment Plant (CWTP). USEPA classified the THMs as Group B2 carcinogens (shown to cause cancer in laboratory animals). This research evaluated the THMs concentrations in the following sampling sites: CWTP, Río Hondo and Piñas Abajo schools, Comerio Health Center (CDT), and the Vázquez Ortiz family, in the municipality of Comerio Puerto Rcio. The results show that the factors affecting the formation of THMs occur in different concentrations across the distribution line. There are not specific ranges to determine the formation of THMs in drinking water when the chemical and physical parameters were evaluated. Three different nanostructured materials (graphene, mordenite (MOR) and multiwalled carbon nanotubes (MWCNTs)) were used in this research, to reduce the THMs formation by adsorption in specific contact times. The results showed that graphene is the best nanomaterial to reduce THMs in drinking water. Graphene can reduce 80 parts per billion (ppb) of THMs in about 2 hours. In addition mordenite can reduce approximately $80 \mathrm{ppb}$ of THMs and MWCNTs adsorbs $71 \mathrm{ppb}$ of THMs in the same period of time respectively. In order to complement the adsorption results previously obtained, total organic carbon (TOC) analyses were measured, after different contact times with the nanomaterials. During the first 30 minutes, graphene $\mathrm{C} / \mathrm{Co}$ 
was reduced to c.a. 0.9, in presence of each THMs solution. MWCNTs and MOR show similar adsorptions trends in comparison with graphene.

\title{
Keywords
}

\author{
Trihalomethanes, Disinfection By-Products (DBPs), Graphene, Mordenite, Multiwalled Carbon \\ Nanotubes
}

\section{Introduction}

In Puerto Rico the water treatment plants are administrated by the Puerto Rico Aqueduct and Sewer Authority (PRASA). The process for treating drinking waters is similar in the majority of drinking water treatment plants (DWTP) in Puerto Rico because they use chlorine as a disinfectant to produce drinking water quality for consumption. These processes begin with pre-chlorination in the water intake, and then the water passes to a mixing chamber where Polymer 6803 is added to form sedimentation. The next step is flocculation, where a water softener salt is added. The final mechanical step is the filtration process where a sand filter with activated carbon is used to remove taste and odor. Finally, the water is discharged to the distribution system, and chlorine is applied again to reduce the presence of any pathogenic microorganism. In some water treatment plants, disinfection by-products (DBPs), such as trihalomethanes (THMs) can be formed and in some cases they exceed the maximum contamination limit (MCLs) $(0.080 \mathrm{mg} / \mathrm{L})$ established in Stage 1, Disinfectants and Disinfection Byproducts Rule (DBPR) by the United States Environmental Protection Agency (USEPA) [1]. In addition the evaluation of historical data of drinking water from PRASA shows a serious problem of water quality in terms of VOC in drinking water. The principal municipalities with this problem in Puerto Rico are: Aibonito, Aguas Buenas, Bayamon, Caguas, Canovanas, Cidra, Gurabo, Isabela, San Juan, Toa Baja, and Quebradillas. In these municipalities THMs were detectable more than two times in a year.

\section{Trihalomethanes (THMs)}

\subsection{Chemistry of THMs}

Approximately 600 - 700 DBPs have been reported in the literature as the major disinfectants used (chlorine, ozone, chlorine dioxide, chloramines) as well as their combinations. DBPs are the result from the reactions between organic and inorganic matter in water with chemical treatment agents during the water disinfection process. The THMs are halogen-substituted single carbon compounds with the general formula $\mathrm{CHX}_{3}$, where $\mathrm{X}$ may be fluorine, chlorine, bromine or iodine or combination thereof. There are four of these combinations: chlorodibromomethane $\left(\mathrm{CHClBr}_{2}\right)$, bromoform $\left(\mathrm{CHBr}_{3}\right)$, chloroform $\left(\mathrm{CHCl}_{3}\right)$ and bromodichloromethane $\left(\mathrm{CHBrCl}_{2}\right)$ (Hua et al. 2010, Karim et al. 2011). Chemically, the formation of THMs (specifically compounds based on chlorine) occurs in the chlorination process when the chlorine $\left(\mathrm{Cl}_{2}\right)$ is added to water and is dissolved in the medium of interest. The $\mathrm{Cl}_{2}$ molecule (with zero oxidation state) rapidly undergoes a disproportionation reaction in which one of the chlorine atoms is reduced to chloride $\mathrm{Cl}^{-}$and the other is oxidized to $\mathrm{Cl}^{+}$, a highly reactive species that rapidly displaces a proton from water to form hypochlorous acid (HOCl). The overall result is the hydrolysis of the $\mathrm{Cl}_{2}$ molecule.

$$
\begin{gathered}
\mathrm{Cl}_{2}+\mathrm{H}_{2} \mathrm{O} \leftrightarrow \mathrm{HCl}+\mathrm{HClO} \\
\mathrm{K}_{\mathrm{a}}\left(20^{\circ} \mathrm{C}\right)=3.3 \times 10^{4}
\end{gathered}
$$

Hypochlorous acid is a weak acid that undergoes partial dissociation in an alkaline pH to form the hypochlorite ion $\left(\mathrm{OCl}^{-}\right)[2]$.

$$
\begin{gathered}
\mathrm{HOCl}+\mathrm{H}_{2} \mathrm{O} \leftrightarrow \mathrm{H}^{+}+\mathrm{OCl}^{-} \\
\mathrm{K}_{\mathrm{a}}=2.7 \times 10^{-8}
\end{gathered}
$$

The addition of hypochlorite ion produces a dissociation to form $\mathrm{OH}^{-}$[2].

$$
\mathrm{OCl}^{-}+\mathrm{H}_{2} \mathrm{O} \leftrightarrow \mathrm{HClO}+\mathrm{OH}^{-}
$$




$$
\mathrm{K}_{\mathrm{hb}}=3.7 \times 10^{-7}
$$

The total concentration of $\mathrm{Cl}_{2}, \mathrm{HOCl}$ and $\mathrm{OCl}^{-}$is referred as free available chlorine.

\subsection{Factors Affecting Formation of Disinfection By-Products (DBPs)}

DBPs are the result of a reaction between a disinfecting agent (chemical or physical) and a precursor chemical in the source water. The factors affecting formation of DBPs are: chlorine residual, temperature, contact time, $\mathrm{pH}$, and NOM. Chlorine dose from 2 to $16 \mathrm{mg} / \mathrm{L}$ will lead to an increase of reactions, therefore causing an increase of HAAs and THMs formation [3]. The residual chlorine is define as the sum of the concentration of $\mathrm{Cl}_{2}, \mathrm{HOCl}$ and $\mathrm{OCl}^{-}$and is referred as free available chlorine. Seasonal variations are related to variations of raw water quality, water temperature, and treatment plant operations. In fact, changes in operational parameters during water treatment, for example, chlorine dose and $\mathrm{pH}$ adjustment, are generally a response to changes in both water temperature and raw water quality [4]. The contact time to form THMs or other DBPs should be less than $5 \mathrm{~h}$ (90\%) and levels off at 96 hours [5]. The probability of THMs formation increases in pH range from 7.0 to 9.0, no positive effect at $\mathrm{pH}>9.5$ [5]. NOM is composed of an heterogeneous mixture of humic substances (HS), carboxylic acids, proteins, amino acids, polysaccharides, hydroxyl acids and other common components of surface waters and are primarily of concern because it is a precursor to the formation of DBPs in drinking water [6] [7].

\subsection{Description of the Study Area}

From 2004 to 2011, THMs concentrations were found in CWTP and at different sampling sites across the water distribution system (Piñas Abajo and Río Hondo schools and Comerio Family Health Center). The present research has been developed with the aim to provide new insights on this situation and to suggest possible solutions. The main objectives of this research can be summarized as: 1) to quantify the THMs concentration in CWTP, Piñas Abajo and Río Hondo schools, Comerio Family Health Center and the residence of Vázquez Ortiz family; 2) to evaluate different nanomaterials to be used as potential adsorbents; and 3) to suggest the use of new nanomaterials to produce drinking water with sufficient quality. According to data of 2010, the municipality of Comerio has an estimated population of 20,778. The CWTP owned and operated by PRASA, supplies drinking water to an estimated $80 \%$ of the Comerio township population. The sampling sites were CWTP, Piñas Abajo and Río Hondo schools, and the Comerio Family Health Center. In addition, a house was selected for comparison purposes (Vázquez Ortiz residence). The water samplings were collected every two weeks for a period of one year. The USEPA 502.2 method was the procedure used to evaluate the THMs concentrations [8]. The water sampling collection began from February 2011 through February 2012.

\subsection{Chemical and Physical Parameters Results}

The average $\mathrm{pH}$ value was 7.84. The lowest $\mathrm{pH}$ value (7.06) was found in CDT on January 13, 2012, while the highest $\mathrm{pH}$ value (8.69) was found in Río Hondo school on 07/01/2011. The average temperature value was $25.7^{\circ} \mathrm{C}$. The minimum temperature value was $20.2^{\circ} \mathrm{C}$ and it was found in Piñas Abajo school on February 25 , 2011. The highest temperature value was $30.5^{\circ} \mathrm{C}$ and it was reported in the same sampling site on August 12 , 2011. The average residual chlorine value was $1.06 \mathrm{mg} / \mathrm{L}$. The lowest value was $0.06 \mathrm{mg} / \mathrm{L}$ on $04 / 08 / 2011 \mathrm{in}$ CWTP and the highest value was $2.20 \mathrm{mg} / \mathrm{L}$ found in CDT on 3/25/2011. The average value of TOC was 1.75 $\mathrm{mg} / \mathrm{L}$. The lowest value was $0.95 \mathrm{mg} / \mathrm{L}$ in CWTP on 08/26/2011 and the highest value was $14.26 \mathrm{mg} / \mathrm{L}$ in Vázquez Ortiz residence on April 8, 2011.

\subsection{THMs Concentrations in Drinking Water}

The average THMs value found in this research was $0.0545 \mathrm{mg} / \mathrm{L}$. The highest value was $0.1101 \mathrm{mg} / \mathrm{L}$ on 02/25/2011 in CDT sampling site. The lowest value was $0.0854 \mathrm{mg} / \mathrm{L}$ on 08/12/2011 in the same sampling site (CDT). THMs formations were found in all sampling sites, moreover, in some sampling sites the THMs formation was detected only one time specifically in (Vázquez Ortiz residence, CWTP, and Río Hondo and Piñas Abajo schools). The major THMs detection in water samples was found in CDT sampling sites for ten times, (Table 1). 
Table 1. THMs concentrations found in this research.

\begin{tabular}{ccc}
\hline Sampling dates & Sampling sites & THMs $(\mathrm{Mg} / \mathrm{L})$ \\
\hline $02 / 25 / 11$ & CDT & 0.1101 \\
$03 / 11 / 11$ & CDT & 0.0922 \\
$03 / 25 / 11$ & CDT & 0.1008 \\
$04 / 08 / 11$ & CDT & 0.0913 \\
$04 / 26 / 11$ & CDT & 0.0935 \\
$05 / 20 / 11$ & CDT & 0.0922 \\
$07 / 01 / 11$ & CDT & 0.0907 \\
$07 / 29 / 11$ & CDT & 0.0898 \\
$08 / 12 / 11$ & CDT & 0.0854 \\
$10 / 07 / 11$ & CDT & 0.0974 \\
$02 / 25 / 11$ & Vázquez & 0.0967 \\
$02 / 25 / 11$ & Piñas & 0.0901 \\
$03 / 25 / 11$ & CWTP & 0.0869 \\
$02 / 25 / 11$ & Río Hondo & 0.0901 \\
\hline
\end{tabular}

\subsection{Physical Alternatives to Reduce THMs Concentrations in Drinking Water}

Different physical approaches can be evaluated to reduce the formation of THMs and to remove them from drinking water. Three different nanostructured materials were tested: multiwalled carbon nanotubes (MWCNTs), zeolites (mordenite), and graphene flakes with the purpose to identify the appropriate nanostructured material to adsorb THMs on their surface. CNTs are being explored as replace of charcoal (activated carbon) because this nanomaterial effectively removes metal and organic contaminants from water [9]. MWCNTs contain between 2 and more than 30 concentric cylinders placed around a common central hollow with spacing between the layers close to that of the interlayer distance in graphite $(0.34 \mathrm{~nm})$. Other characteristics are: Electrical conductivity, optical activity, and mechanical strength.

Zeolites are open-framework structures composed of tetrahedral $\mathrm{SiO}_{4}$ and $\mathrm{AlO}_{4}$, and they are widely used as solid acid/base catalysts. Mordenite (MOR) occupies a special place among zeolites used in adsorption and catalysis thanks to its acid resistance, thermal stability, and acid properties. MOR is a zeolite that consists of two types of channels; one is composed by 12 -member rings $\left(0.67 \times 0.7 \mathrm{~nm}^{2}\right)$ and the other, which comprises the side pockets to the main channels, is composed of 8-member rings $\left(0.26 \times 0.57 \mathrm{~nm}^{2}\right)$ [10]. Graphene is an allotrope of carbon whose structure consists of a single layer of carbon atoms bonded in a hexagonal lattice [11]. It can be viewed as less than 10 layers of graphite. This material has attracted intense scientific interest due to its unique two dimensional structure and remarkable electronic properties [12]. It has a large theoretical specific surface area $\left(2630 \mathrm{~m}^{2} \cdot \mathrm{g}^{-1}\right)([13], 2011)$, high intrinsic mobility $\left(200,000 \mathrm{~cm}^{2} \cdot \mathrm{v}^{-1} \cdot \mathrm{s}^{-1}\right)$, thermal conductivity $\left(\sim 5000 \mathrm{Wm}^{-1} \cdot \mathrm{K}^{-1}\right)$, optical transmittance $(\sim 97.7 \%)$, good electrical conductivity and high mechanical strength [14].

\subsection{Experimental Procedure}

With the aim to test the different nanomaterials as potential adsorbers of THMs, four solutions of each THM were prepared. Solutions of chloroform, bromoform, diclorobromomethane and dibrochloromethane with a concentration of $90 \mathrm{ppb}$ were prepared using $\mathrm{CO}_{2}$-free water and subsequently mixed with the different THMs in an Erlenmeyer flask of $1000 \mathrm{~mL}$. Next, $25 \mathrm{mg}$ of each nanomaterial (MWCNTs, MOR and graphene) were added to each solution. In this step different contact times were measured (30, 60, 120, 180 and 240 minutes, respectively). After completed each contact time, approximately $90 \mathrm{~mL}$ of each sample was transferred to a centrifuge tube and the mixture was centrifuged for 15 minutes at 3000 revolutions per minute (rpm). With the aim to remove all possible residues of nanomaterial, the reaction mixture was also filtered by using disk filters of $0.45 \mu \mathrm{m}$. Samples were analyzed with a TOC analyzer Phoenix 8000 Kekmar Dohrmann and GS-MS Shimadzu GC-MS-QP5050A purge and trap system. Each sample was run in duplicates and the mean value of each sample 
was reported.

\subsection{Characterization of the Nanomaterials}

Figure 1 shows HRTEM (high resolution Transmission Electron Microscopy) images of the graphene used in the present research. As can be seen there, disaggregation apparently was not fully accomplished during the ultrasound treatment in ethanol before observation by HRTEM. In these images, each horizontal line represents a graphene sheet of one atom of thickness.

Mordenite was analyzed by SEM. Figure 2(a) and Figure 2(b) show the crystalline structure with different orientations and aggregations of MOR obtained at low magnification. Figure 2(c), obtained at 50000× corresponds to a single crystal of MOR.

MWCNTs were also characterized by SEM. As can be seen in Figure 3(a), at low magnification agglomerations of MWCNTs with different shapes and particle size can be observed. At higher magnification these small aggregates can be observed as mixed fibers (see Figure 3(b)). Each of these fibers corresponds to a multiwalled carbon nanotube.
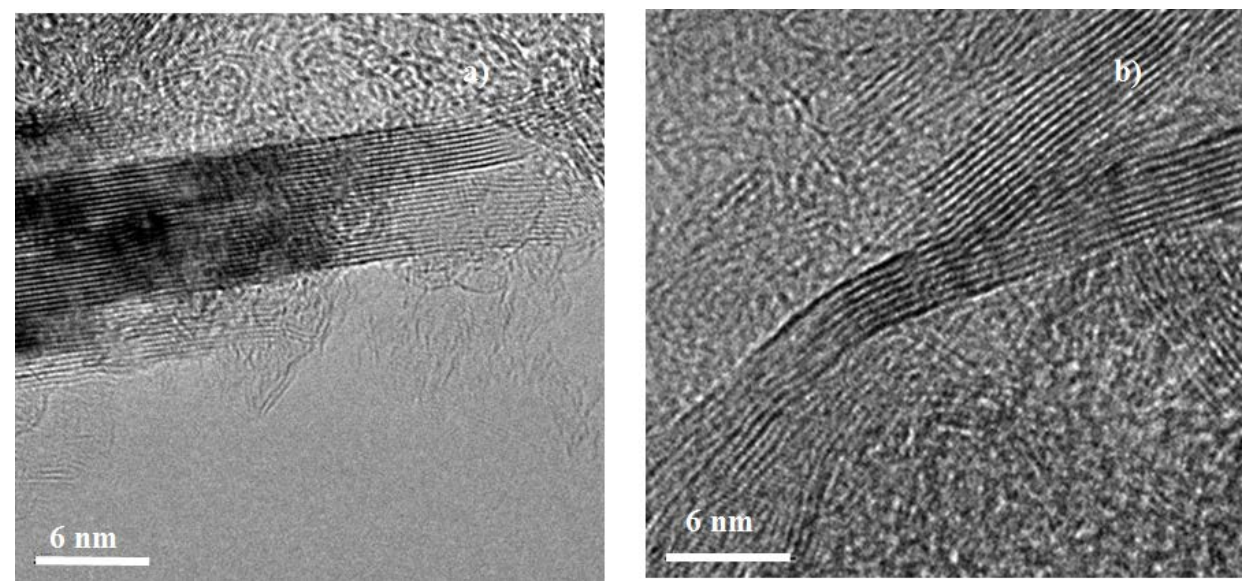

Figure 1. HRTEM images of graphene flakes, bar $=6 \mathrm{~nm}$.

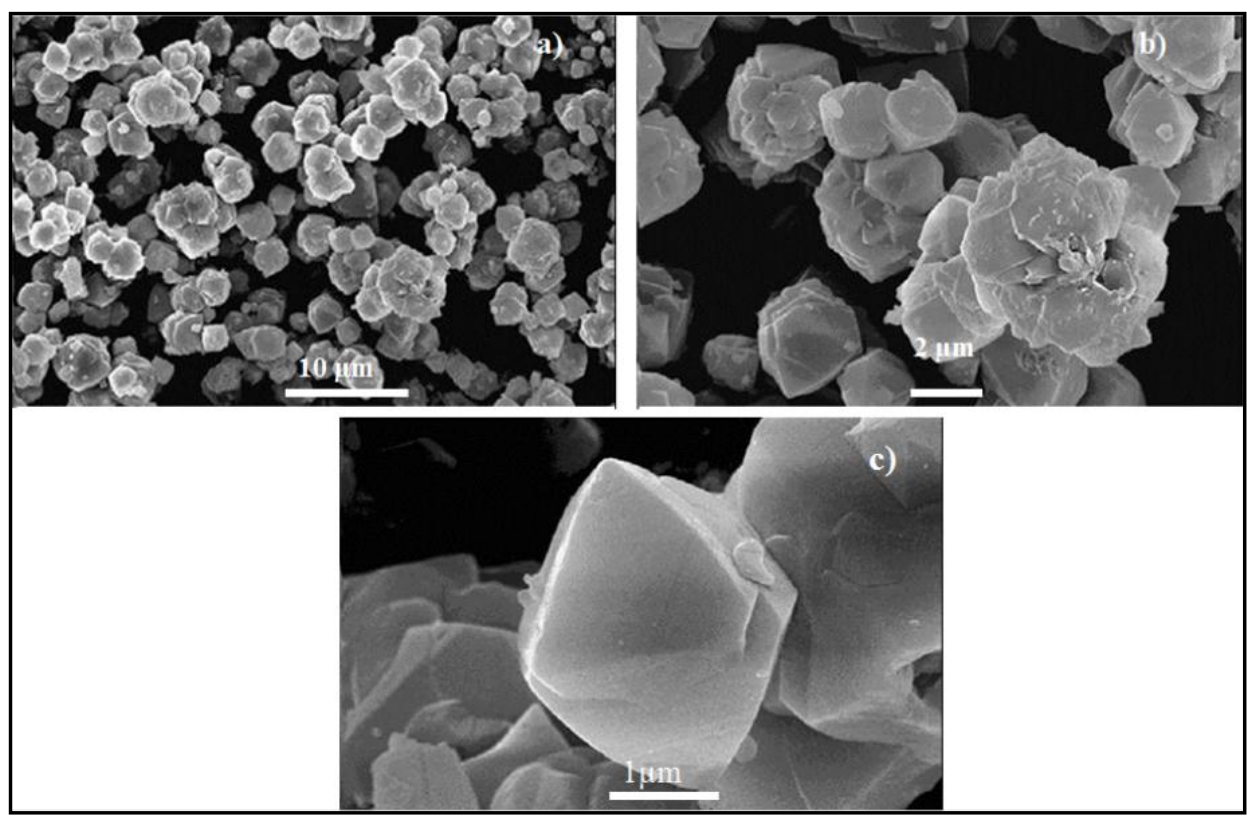

Figure 2. SEM micrographs of MOR showing the typical crystalline structure at $5000 \times$ (a) and $15000 \times(b)$, and detail of a single cystal observed at 50000× (c). 

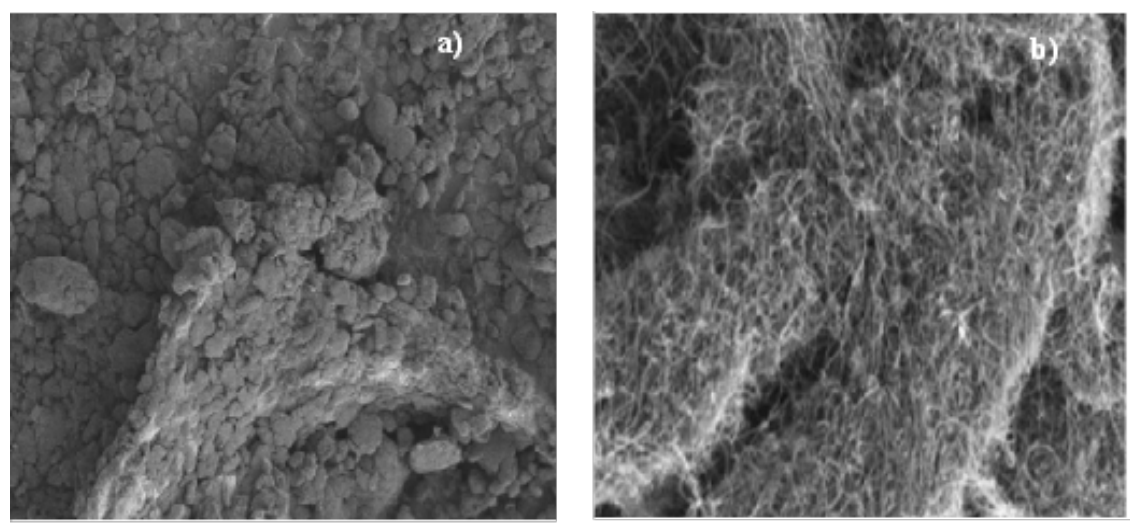

Figure 3. MWCNTs observed by SEM at low magnification (a) showing compact aggregates of bundles; and MWCNTs observed at higher magnification (b).

Graphene flakes used in this research showed the highest specific surface area BET with a value of ca. 1850 $\mathrm{m}^{2} / \mathrm{g}$. This BET result means that graphene has potentially more adsorption capacity than MOR $\left(420 \mathrm{~m}^{2} / \mathrm{g}\right)$ and MWCNTs $\left(585 \mathrm{~m}^{2} / \mathrm{g}\right)$, respectively.

Although MWCNTs has more BET surface area than MOR, carbon nanotubes have lesser capacity of adsorption (with some contaminants such as THMs) than MOR. MOR was the nanomaterial with the lowest BET surface area found in this research, with a value of $420 \mathrm{~m}^{2} / \mathrm{g}$. Although MOR has a lower surface area in comparison with MWCNTS and graphene, MOR is composed by monodirectional channels that can increase the adsorption into the inner pore structure. On the other hand, the high $\mathrm{Si} / \mathrm{Al}$ atomic ratio of this material indicates the presence of acid sites that can increase the efficiency of interaction with other compounds (i.e. THMs).

\subsection{THMs Adsorption by Nanomaterials}

The adsorption of each nanomaterial was measured in different contact times of each THMs. Graphene was found to be the nanomaterial with the highest adsorption capacity for THMs. In the first 30 minutes graphene adsorbed $61.2 \mathrm{ppb}$ of $\mathrm{CHCl}_{3}, 66.5 \mathrm{ppb}$ of $\mathrm{CHBr}_{3}, 59.1 \mathrm{ppb}$ of $\mathrm{Br}_{2} \mathrm{CHCl}$ and $51.2 \mathrm{ppb}$ of $\mathrm{BrCHCl}_{2}$. After 1 hour, graphene adsorbed $78.2 \mathrm{ppb}, 80.2 \mathrm{ppb}, 75.7 \mathrm{ppb}$, and $66.6 \mathrm{ppb}$ of $\mathrm{CHCl}_{3}, \mathrm{CHBr}_{3} \mathrm{Br}_{2} \mathrm{CHCl}$, and $\mathrm{BrCHCl}_{2}$ respectively.

The adsorption process in graphene is very fast during the first 120 minutes, where graphene adsorbed the majority of THMs. At contact time of 120 min graphene was able to absorb the following concentrations of THMs: $84.2 \mathrm{ppb}$ of $\mathrm{CHCl}_{3}, 85.8 \mathrm{ppb}$ of $\mathrm{CHBr}_{3}, 88.3 \mathrm{ppb}$ of $\mathrm{Br}_{2} \mathrm{CHCl}$ and $80 \mathrm{ppb}$ of $\mathrm{BrCHCl}_{2}$. At this contact time is when graphene adsorbed $80 \mathrm{ppb}$ or higher, being this concentration the MCL of THMs in drinking water. The reason for the extremely high adsorption capacity of graphene is possibly due to the high specific surface area in comparison with MOR and MWCNTs. Graphene is formed by flakes of single layers or associations of no more than 6 - 7 sheets (as was observed by HRTEM), being this fact the reason for the high surface area and the high adsorption capacity.

In the first 30 minutes MOR adsorbed $45.2 \mathrm{ppb}$ of $\mathrm{CHCl}_{3}, 54.7 \mathrm{ppb}$ of $\mathrm{CHBr}_{3}, 44 \mathrm{ppb}$ of $\mathrm{Br}_{2} \mathrm{CHCl}$ and 36.1 $\mathrm{ppb}$ of $\mathrm{BrCHCl}_{2}$. The adsorption process of THMs by MOR is very fast during the first 60 minutes, when $70 \mathrm{ppb}$ of $\mathrm{CHCl}_{3}, 75.8 \mathrm{ppb}$ of $\mathrm{CHBr}_{3}, 66.8 \mathrm{ppb}$ of $\mathrm{Br}_{2} \mathrm{CHCl}$ and $57.2 \mathrm{ppb}$ of $\mathrm{BrCHCl}_{2}$ were adsorbed. In 120 minutes MOR adsorbed $81 \mathrm{ppb}$ of $\mathrm{CHCl}_{3}, 85.6 \mathrm{ppb}$ of $\mathrm{CHBr}_{3}, 78.2 \mathrm{ppb}$ of $\mathrm{Br}_{2} \mathrm{CHCl}$ and $74 \mathrm{ppb}$ of $\mathrm{BrCHCl}_{2}$. As occurred for graphene, at this contact time $(120 \mathrm{~min}) \mathrm{MOR}$ adsorbed $80 \mathrm{ppb}$ or higher concentrations of $\mathrm{CHCl}_{3}$ and $\mathrm{CHBr}_{3}$, being this concentration the MCL of THMs in drinking water. In the case of $\mathrm{Br}_{2} \mathrm{CHCl}$ and $\mathrm{BrCHCl}_{2}$, MOR adsorbed over $80 \mathrm{ppb}$ after 180 minutes of contact time $\left(\mathrm{Br}_{2} \mathrm{CHCl}(81.7 \mathrm{ppb}), \mathrm{BrCHCl}_{2}(81.3 \mathrm{ppb})\right.$ ). After 240 minutes the process is completed with a final adsorption of $89.4 \mathrm{ppb}\left(\mathrm{CHCl}_{3}\right), 92.4 \mathrm{ppb}$ of $\mathrm{CHBr}_{3}, 87.5 \mathrm{ppb}$ of $\mathrm{Br}_{2} \mathrm{CHCl}$ and $84.9 \mathrm{ppb}$ of $\mathrm{BrCHCl}_{2}$. MOR is a mono directional zeolite with channels organized in 12 member rings. Due to this particular structure, MOR is able to incorporate pollutants inside their internal channels and also to absorb them on the surface.

In this research MWCNTs was to be found the nanomaterial with the lowest adsorption capacity in comparison with graphene and MOR. During the first 30 minutes, MWCNTs adsorbed $32 \mathrm{ppb}, 30.2 \mathrm{ppb}, 24 \mathrm{ppb}$ and $20.8 \mathrm{ppb}$ of $\mathrm{CHCl}_{3}, \mathrm{CHBr}_{3}, \mathrm{Br}_{2} \mathrm{CHCl}$ and $\mathrm{BrCHCl}_{2}$, respectively. The adsorption process experienced by this 
nanomaterial is lower in comparison with graphene and MOR, for example after 60 minutes MWCNTs adsorbed $54 \mathrm{ppb}$ of $\mathrm{CHCl}_{3}, 47.7 \mathrm{ppb}$ of $\mathrm{CHBr}_{3}, 55.6 \mathrm{ppb}$ of $\mathrm{Br}_{2} \mathrm{CHCl}$ and $46.9 \mathrm{ppb}$ of $\mathrm{BrCHCl}_{2}$. After 120 minutes, MWCNTs does not complete the adsorption of $80 \mathrm{ppb}$ (MCL) in each solution; only $71 \mathrm{ppb}$ of $\mathrm{CHCl}_{3}, 69.2 \mathrm{ppb}$ of $\mathrm{CHBr}_{3}$, $55.6 \mathrm{ppb}$ of $\mathrm{Br}_{2} \mathrm{CHCl}$ and $66 \mathrm{ppb}$ of $\mathrm{BrCHCl}_{2}$ were adsorbed. MWCNTs adsorbed $80 \mathrm{ppb}$ or higher concentrations after 180 minutes of contact time ( $80 \mathrm{ppb}$ of $\mathrm{CHCl}_{3}$ and $82.5 \mathrm{ppb}$ of $\mathrm{BrCHCl}_{2}$ ). At 240 minutes $84.7 \mathrm{ppb}$ of $\mathrm{CHBr}_{3}$, and $85.1 \mathrm{ppb}$ of $\mathrm{Br}_{2} \mathrm{CHCl}$ were adsorbed by MWCNTs. The results observed using MWCNTs are currently being analysed and further experiments are performed to determine the significance of this unexpected behavior.

The adsorption behavior of THMs by graphene, MOR and MWCNTs is summarized in Figures 4-7, corresponding to the adsorption results of each pollutant on the three nanostructured materials.

\subsection{NOM Adsorption by Nanomaterials}

In order to complement the adsorption results previously obtained, total organic carbon (TOC) analyses were measured, after different contact times with the nanomaterials, using the same solutions that those used to study

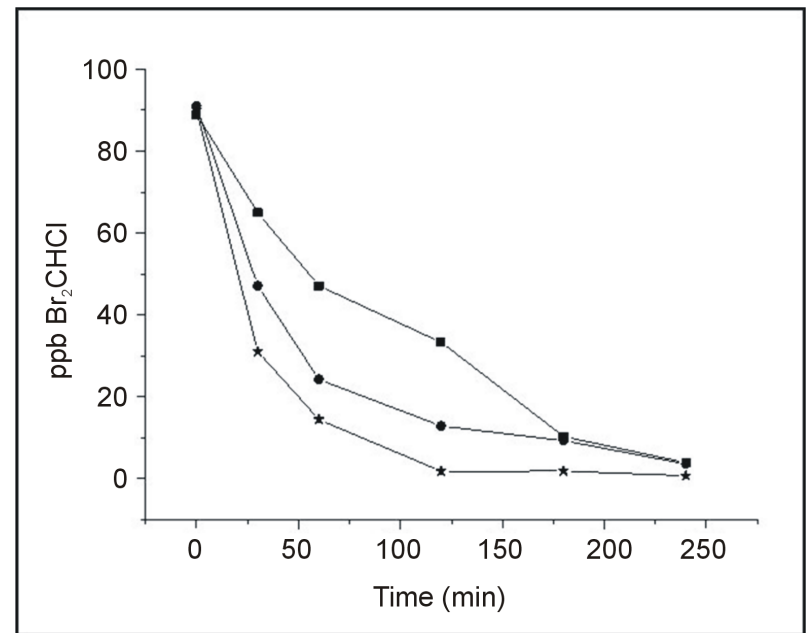

Figure 4. Chlorodibromomethane adsorption by the different nanomaterials used in this research at different contact times. Graphene (*) MOR (•), MWCNTs (•).

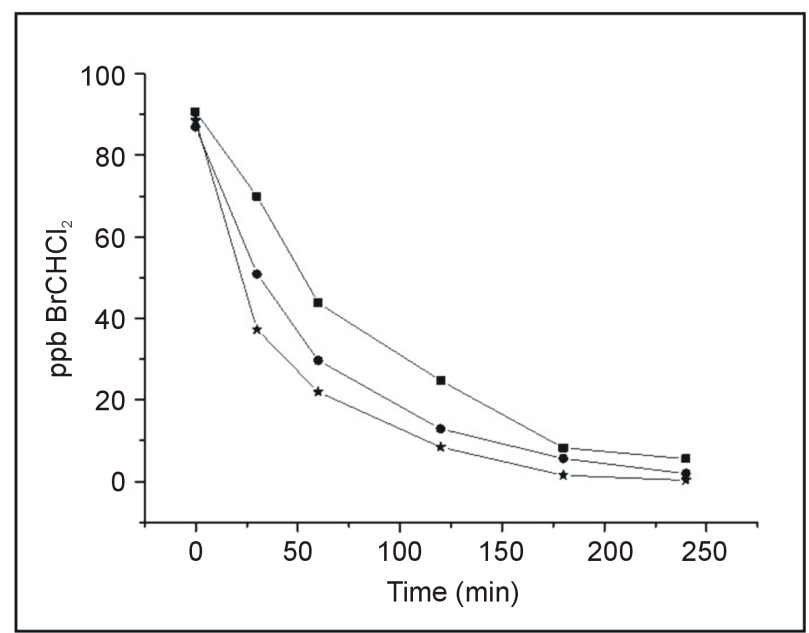

Figure 5. Bromodichloromethane adsorption by the different nanomaterials used in this research at different contact times. Graphene (*) MOR (•), MWCNTs (•). 


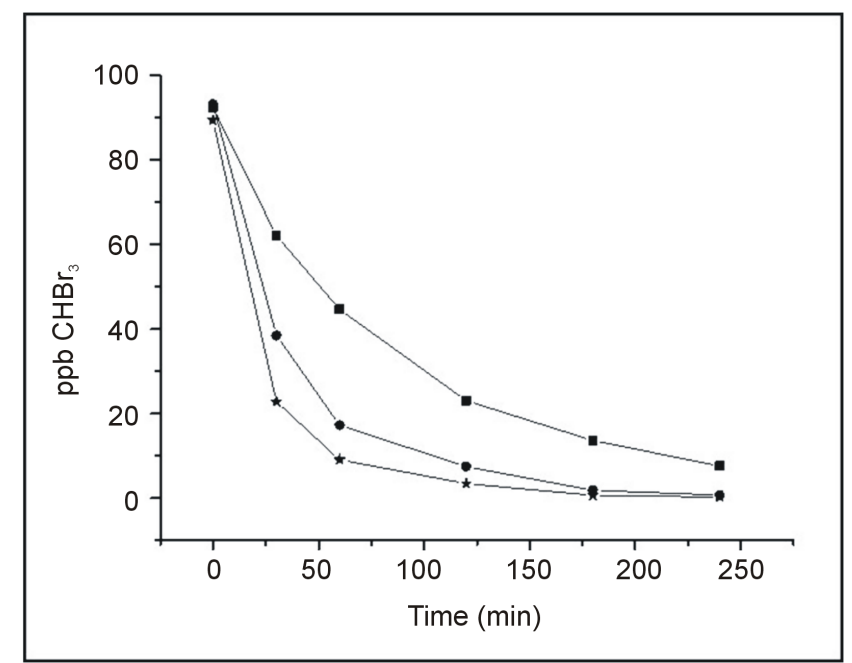

Figure 6. Bromoform adsorption by the different nanomaterials used in this research at different contact times. Graphene $\left(^{*}\right)$ $\operatorname{MOR}(\bullet)$, MWCNTs (•).



Figure 7. Chloroform adsorption by the different nanomaterials used in this research at different contact times. Graphene $\left(^{*}\right)$ MOR (•), MWCNTs (•).

the THMs adsorption. Figures 8-11, show the C/Co ratio, where $\mathrm{C}$ is the TOC concentration measured at different contact times, and $\mathrm{Co}$ is the TOC concentration measured before addition of the nanomaterial (zero time). At zero time, C/Co is always 1.0 in each THMs solution. In the case of graphene, during the first 30 minutes C/Co was reduced to c.a. 0.9, in presence of each THMs solution. In all cases, after 60 minutes C/Co decreased to 0.7. After 2 hours, $\mathrm{C} / \mathrm{Co}$ was found to be in the range of 0.4 to 0.5 (Figures 8-11). After 240 minutes, graphene was able to adsorb the majority of the organic matter present in the solution as THMs (C/Co was reduced to ca. 0.2 ).

\section{Discussion}

THMs concentrations exceeding MCL established by USEPA are present in drinking water of Puerto Rico. The chemical and physical parameters measured in this research demonstrated that the THMs formation occurs in $\mathrm{pH}$ ranging from 7.34 to 8.19. The temperature for THMs formation ranged from $20.2^{\circ} \mathrm{C}$ to $27.9^{\circ} \mathrm{C}$. The residual chlorine for THMs formations ranged from $0.08 \mathrm{mg} / \mathrm{L}$ to $2.20 \mathrm{mg} / \mathrm{L}$. The TOC concentrations where the major 
THMs were formed ranged from $1.01 \mathrm{mg} / \mathrm{L}$ to $5.83 \mathrm{mg} / \mathrm{L}$. THMs were detected in ten occasions with a major detection in CDT sampling site, due possibly to the presence of a water tank. This water storage increases the accumulation of NOM and therefore the THMs formation. In addition, in Río Hondo and Piñas Abajo schools, CWTP and Vázquez Ortiz residence, THMs were measured only in one occasion. The formation of THMs is influenced by some factors such as: NOM, $\mathrm{pH}$, residual and temperature. In our research, the adsorption studies of THMs by the three selected nanomaterials show that graphene has the highest capacity of adsorption. Graphene has an extremely high surface area in comparison with MOR and MWCNTs. This enormous surface area, together with the special structure of this material, increases the exposure of graphene to contaminants. Graphene adsorbs $80 \mathrm{ppb}$ of each THM after 120 minutes of contact time, in comparison with MOR and MWCNTs that require higher contact times. MOR requires 120 minutes to adsorb $80 \mathrm{ppb}$ of $\mathrm{CHCl}_{3}$ and $\mathrm{CHBr}_{3}$ and 180 minutes

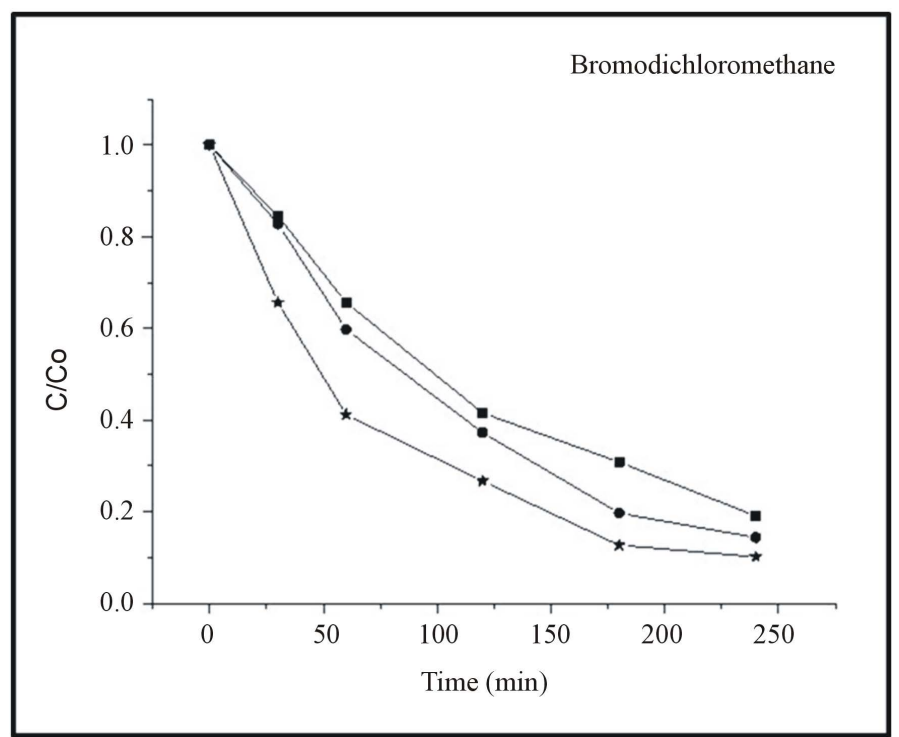

Figure 8. Bromodichloromethane adsorption (TOC) by the different nanomaterials used in this research at different contact times. Graphene $(*) \operatorname{MOR}(\bullet)$, MWCNTs (•).

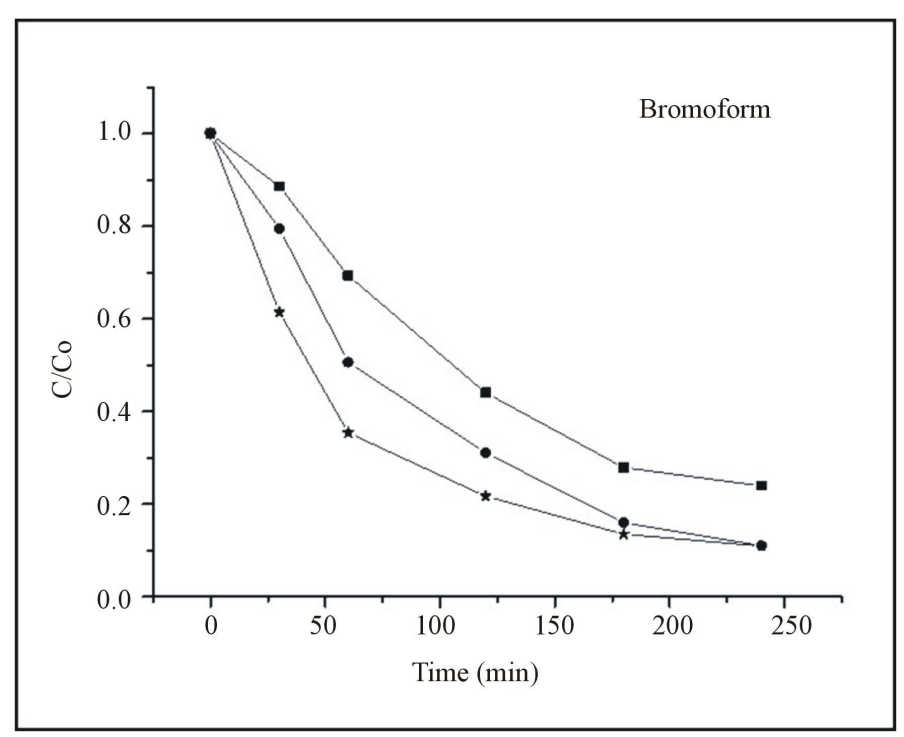

Figure 9. Bromoform adsorption (toc) by the different nanomaterials used in this research at different contact times. Graphene $(*)$ MOR (•), MWCNTs ('). 


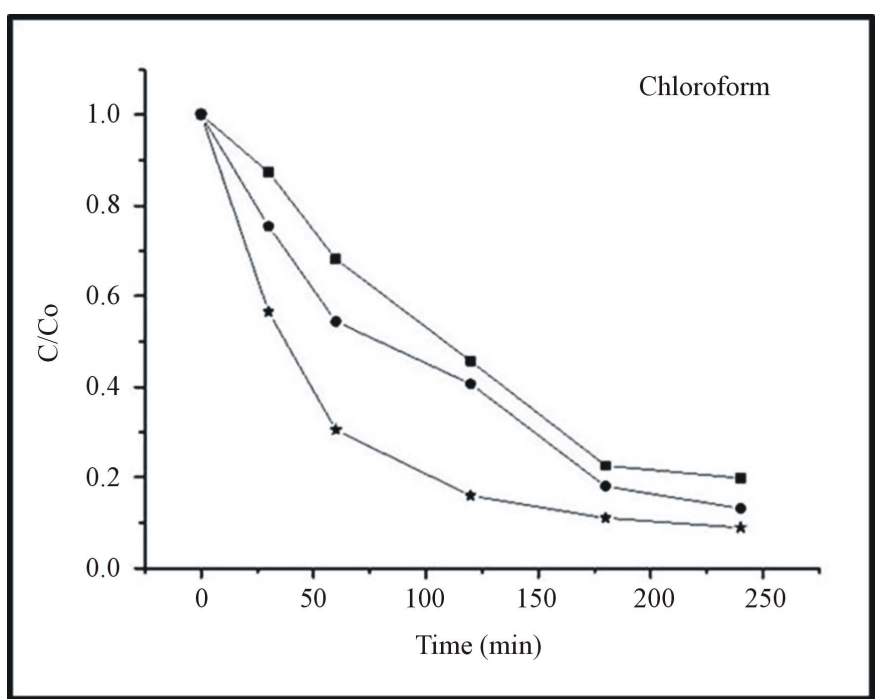

Figure 10. Chloroform adsorption (toc) by the different nanomaterials used in this research at different contact times. Graphene $\left(^{*}\right)$ MOR (•), MWCNTs (•).

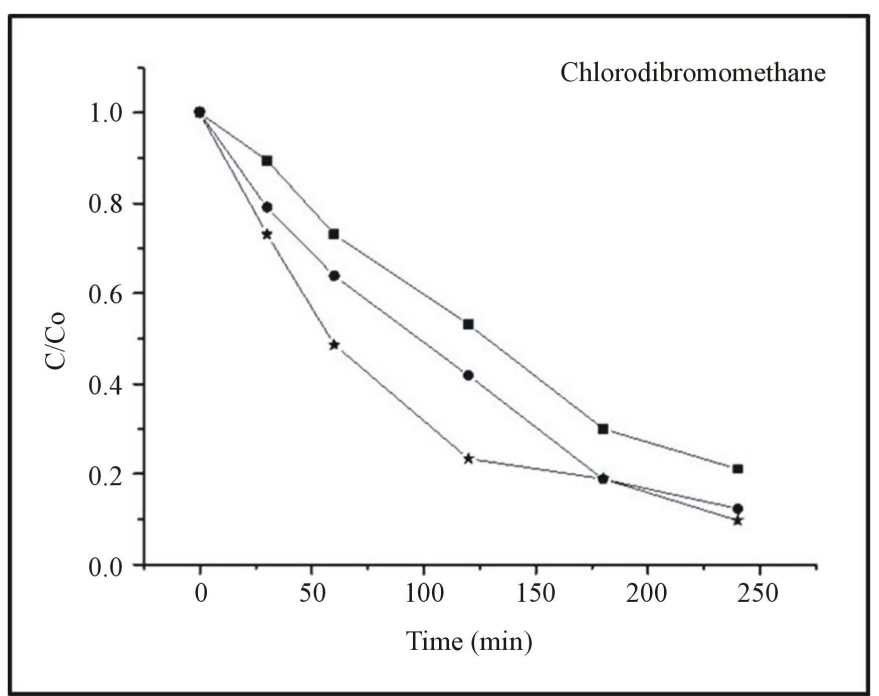

Figure 11. Chlorodibromomethane adsorption (toc) by the different nanomaterials used in this research at different contact times. Graphene $(*)$ MOR (•), MWCNTs (•).

to adsorb $\mathrm{Br}_{2} \mathrm{CHCl}$ and $\mathrm{BrCHCl}_{2}$ respectively. MWCNTs adsorbs $80 \mathrm{ppb}$ or higher after 180 minutes of contact times of each THMs. Therefore the MCL of THMs in water $(0.080 \mathrm{mg} / \mathrm{L})$ established by USEPA could be accomplished by adsorption after two hours if graphene is used as adsorbent in water treatment plants (at least if similar parameters used in this research are implemented in the water treatment plants). Graphene is the best nanomaterial to reduce THMs in drinking water treatment plants.

\section{References}

[1] Nikolaou, A., Rizzo, L. and Selcuk, H. (2007) Control of Disinfection By-Products in Drinking Water Systems. Nova Science Publisher, Inc., New York, 216.

[2] Barrenetxea, C.O., Serrano, A.P., Delgado, M.G., Vidal, F.R. and Blanco, J.A. (2003) Contaminación ambiental. Una visión desde la química. [Environmental Contamination, a Chemistry Point of View]. Departamento de Química, Escuela Politécnica Superior, Universidad de Burgos, Thomson Editores, Spain, 153. 
[3] Sun, Y.X., Wu, Y.Q., Hu, H.Y. and Tian, J. (2009) Effects of Operating Conditions on THMs and HAAs Formation during Wastewater Chlorination. Journal of Hazardous Materials, 168, 1290-1295. http://dx.doi.org/10.1016/j.jhazmat.2009.03.013

[4] Rodríguez, M.J., Serodes, J.B., Levallois, P. and Proulx, F. (2007) Chlorinated Disinfection By-Products in Drinking Water According to Source, Treatment, Season, and Distribution Location. Journal Environmental Engineering Science, 6, 355-365. http://dx.doi.org/10.1139/s06-055

[5] Nikolaou, D.A., Golfinopoulos, K.S., Lekkas, T.D. and Arhonditsis, G.B. (2004) Factors Affecting the Formation of Organic By-Products during Water Chlorination: A Bench-Scale Study. Water Air and Soil Pollution, 159, 357-371. http://dx.doi.org/10.1023/B:WATE.0000049189.61762.61

[6] Liu, S., Lim, M., Fabris, R., Chow, C., Drikas, M. and Amal, R. (2008) $\mathrm{TiO}_{2}$ Photocatalysis of Natural Organic Matter in Surface Water: Impact on Trihalomethanes and Haloacetic Acid Formation Potential. Environmental Science and Technology, 42, 6218-6223. http://dx.doi.org/10.1021/es800887s

[7] Chowdhury, F.L., Berube, P.R. and Mohseni, M. (2008) Characteristics of Natural Organic Matter and Formation of Chlorinated Disinfection By-Products from Two Source Waters That Respond Differently to Ozonation. Science and Engineering, 30, 321-331.

[8] Slater, R.W. and Ho, J.S. (1989) Method 502.2 Volatile Organic Compounds in Water by Purge and Trap Capillary Column Gas Chromatographic with Photoionization and Electrolytic Conductivity Detectors in Series Revision 2. National Exposure Research Laboratory Office of Research and Development US Environmental Protection Agency Cincinnati, Ohio.

[9] Qu, X., Brame, J., Li, Q. and Álvarez, J.J.P. (2012) Nanotechnology for a Safe and Sustainable Water Supply: Enabling Integrated Water Treatment and Reuse. Department of Civil and Environmental Engineering, Rice University, Houston.

[10] Tago, T., Aoki, D., Iwakai, K. and Masuda, T. (2009) Preparation for Size-Controlled MOR Zeolite Nanocrystal Using Water/Surfactant/Organic Solvent. Topics in Catalysis, 52, 865-871. http://dx.doi.org/10.1007/s11244-009-9227-z

[11] Sun, Z., Dustin, K.J. and Tour, J.M. (2011) Graphene Chemistry: Synthesis and Manipulation. The Journal Physical Chemistry Letters, 2, 2425-2432. http://dx.doi.org/10.1021/jz201000a

[12] Feng, X., Maier, S. and Salmeron, M. (2012) Water Splits Epitaxial Graphene and Intercalates. Journal of the American Chemical Society, 134, 5662-5668. http://dx.doi.org/10.1021/ja3003809

[13] Rao, C.N.R., Subrahmanyam, K.S., Ramakrishna, H.S.S. and Govindaraj, A. (2011) Graphene: Synthesis, Functionalization and Properties. Modern Physics Letters, 25, 427-451. http://dx.doi.org/10.1142/S0217984911025961

[14] Ghosh, D., Giri, S., Kalra, S. and Das, C.K. (2012) Synthesis and Characterizations of $\mathrm{TiO}_{2}$ Coated Multiwalled Carbon Nanotubes/Graphene/Polyaniline Nanocomposite for Supercapacitor Applications. Open Journal of Applied Sciences, 2, 70-77. http://dx.doi.org/10.4236/ojapps.2012.22009 